\section{BMJ Open Respiratory Research}

\title{
CPAP delivered outside critical care during the second wave of COVID-19: outcomes from a UK respiratory surge unit
}

Rebecca Nightingale (D) , ${ }^{1,2}$ Joseph Lewis, ${ }^{1,2,3}$ Katelyn Rhiannon Monsell, ${ }^{2}$ Lewis Jones, ${ }^{2}$ Christopher Smith, ${ }^{2}$ Shantanu Kundu, ${ }^{4}$ Helena Bond, ${ }^{2}$ Hassan Burhan, ${ }^{1,2}$ Tom Fletcher, ${ }^{1,2}$ Thomas Blanchard, ${ }^{1,2,3}$ Michael Beadsworth, ${ }^{1,2}$ Peter Hampshire, ${ }^{2}$ Manish Gautam, ${ }^{2}$ Stacy Todd, ${ }^{2}$ Gareth Jones, ${ }^{2}$ Stephen Aston ${ }^{2,3}$

To cite: Nightingale $R$, Lewis J, Monsell KR, et al. CPAP delivered outside critical care during the second wave of COVID-19: outcomes from a UK respiratory surge unit. BMJ Open Resp Res 2021;8:e000907. doi:10.1136/ bmjresp-2021-000907

- Additional supplemental material is published online only. To view, please visit the journal online (http://dx.doi. org/10.1136/bmjresp-2021000907).

GJ and SA contributed equally.

Received 19 February 2021 Accepted 7 August 2021

Check for updates

\section{(c) Author(s) (or their} employer(s)) 2021. Re-use permitted under CC BY-NC. No commercial re-use. See rights and permissions. Published by BMJ.

For numbered affiliations see end of article.

Correspondence to Dr Rebecca Nightingale; rebecca.nightingale@|stmed. ac.uk

\section{ABSTRACT}

Background NHS England recommends noninvasive continuous positive airway pressure (CPAP) as a possible treatment for type 1 respiratory failure associated with COVID-19 pneumonitis, either to avoid intubation or as a ceiling of care. However, data assessing this strategy are sparse, especially for the use of CPAP as a ceiling of care, and particularly when delivered outside of a traditional critical care environment. We describe a cohort of patients from Liverpool, UK, who received CPAP on a dedicated respiratory surge unit at the start of the second wave of the COVID-19 pandemic in UK.

Methods Retrospective cohort analysis of consecutive patients receiving CPAP for the treatment of respiratory failure secondary to COVID-19 on the respiratory surge unit at the Royal Liverpool Hospital, Liverpool, UK from 21 September until 30 November 2020.

Results 88 patients were included in the analysis. $56 / 88$ (64\%) were deemed suitable for escalation to invasive mechanical ventilation (IMV) and received CPAP as a trial; $32 / 88(36 \%)$ received CPAP as a ceiling of care. Median age was 63 years (IQR: 56-74) and $58 / 88$ (66\%) were men. Median $\mathrm{SpO}_{2} / \mathrm{FiO}_{2}$ immediately prior to CPAP initiation was 95 (92-152). Among patients for escalation to IMV, the median time on CPAP was 6 days (IQR 4-7) and survival at day 30 was $84 \%(47 / 56)$ with $14 / 56(25 \%)$ escalated to IMV. Of those patients for whom CPAP was ceiling of care, the median duration of CPAP was 9 days (IQR 7-11) and $18 / 32$ (56\%) survived to day 30 . Pulmonary barotrauma occurred in $9 \%$ of the cohort. There were no associations found on multivariant analysis that were associated with all-cause 30-day mortality. Conclusions With adequate planning and resource redistribution, CPAP may be delivered effectively outside of a traditional critical care setting for the treatment of respiratory failure due to COVID-19. Clinicians delivering CPAP to patients with COVID-19 pneumonitis should be alert to the dangers of pulmonary barotrauma. Among patients who are for escalation of care, the use of CPAP may avoid the need for IMV in some patients. Our data support the NHS England recommendation to consider CPAP as a ceiling of care.

\section{KEY MESSAGES \\ $\Rightarrow$ What is key question: Was providing continuous positive airway pressure (CPAP) to patients with COVID-19 outside the walls of critical care safe and effective in the context of the current pandemic? \\ $\Rightarrow$ What is the bottom line? In this context, CPAP ap- peared be a safe and effective treatment for type 1 respiratory failure in COVID-19. \\ $\Rightarrow$ Why read on? Find out which patient population we delivered CPAP to and how this service was opera- tionally delivered.}

\section{INTRODUCTION}

To date, SARS-CoV-2 - the causal agent of COVID-19-has infected over 100 million people worldwide resulting in over 2 million deaths. ${ }^{1}$ In the UK, $10 \%-15 \%$ of individuals with COVID-19 have required admission to hospital with the majority experiencing varying degrees of type 1 respiratory failure and $17 \%$ requiring admission to critical care. $^{2-4}$

The optimal modality for respiratory support for individuals with COVID-19 who remain hypoxic despite standard oxygen therapy (administered via nasal cannulae (prongs) or Venturi face mask) is uncertain. During the early period of the pandemic, practice varied considerably with some centres opting for early initiation of invasive mechanical ventilation (IMV) in a large proportion of patients failing on standard oxygen therapy. Early reports of high mortality among invasively ventilated patients, as well as constraints on the availability of critical care beds, prompted the increased use of non-invasive continuous positive airway pressure (CPAP) ventilation. Accordingly, NHS England guidance issued in March 2020 suggested that CPAP may be 
Table 1 Baselines characteristics of patients starting CPAP stratified by escalation status

\begin{tabular}{|c|c|c|c|}
\hline & For escalation to IMV $(n=56)$ & $\begin{array}{l}\text { CPAP ceiling of care* } \\
(n=32)\end{array}$ & $\begin{array}{l}\text { Whole cohort } \\
(n=88)\end{array}$ \\
\hline Age (median, IQR) & $60(53-65)$ & $76(64-82)$ & $63(56-74)$ \\
\hline \multicolumn{4}{|l|}{ Age (years) } \\
\hline$<50$ & $10(18 \%)$ & $1(3 \%)$ & $11(13 \%)$ \\
\hline $50-59$ & $16(29 \%)$ & $3(9 \%)$ & $19(22 \%)$ \\
\hline $60-69$ & $22(39 \%)$ & $9(28 \%)$ & $31(35 \%)$ \\
\hline $70-79$ & $8(14 \%)$ & $8(25 \%)$ & $16(18 \%)$ \\
\hline$\geq 80$ & $0(0) \%)$ & $11(34 \%)$ & $11(13 \%)$ \\
\hline Male & $39(70 \%)$ & $19(60 \%)$ & $58(66 \%)$ \\
\hline BMI $\left(\mathrm{kg} / \mathrm{m}^{2}\right)$ & $31(28-33)$ & $32(28-36)$ & $31(28-34)$ \\
\hline Pre-hospital symptom duration & $9(7-10)$ & $7(6-10)$ & $8(7-10)$ \\
\hline Diabetes & $17(30 \%)$ & $15(47 \%)$ & $32(36 \%)$ \\
\hline Hypertension & $24(43 \%)$ & $26(82 \%)$ & $50(57 \%)$ \\
\hline Asthma & $5(9 \%)$ & $4(13 \%)$ & $9(10 \%)$ \\
\hline COPD & $2(4 \%)$ & $4(13 \%)$ & $6(7 \%)$ \\
\hline Other cardiac condition & $8(14 \%)$ & $13(47 \%)$ & $21(24 \%)$ \\
\hline OSA & $4(7 \%)$ & $1(3 \%)$ & $5(6 \%)$ \\
\hline Other comorbid illness & $26(46 \%)$ & $22(69 \%)$ & $48(55 \%)$ \\
\hline \multicolumn{4}{|l|}{ Smoked } \\
\hline Never & $38(68 \%)$ & $18(56 \%)$ & $56(64 \%)$ \\
\hline Ever & $14(25 \%)$ & $13(41 \%)$ & $27(30 \%)$ \\
\hline Current & $4(7 \%)$ & $1(3 \%)$ & $5(6 \%)$ \\
\hline Clinical frailty scale $\mathrm{e}^{22}$ & $1(1-2)$ & $4(3-5)$ & $2(1-3)$ \\
\hline Mortality 4 C Score ${ }^{23}$ & $19 \%(12 \%-27 \%)$ & $41 \%(24 \%-52 \%)$ & $23 \%(14 \%-40 \%)$ \\
\hline \multicolumn{4}{|l|}{ Exercise tolerance $(\mathrm{m})^{\dagger}$} \\
\hline$>1500$ & 37 (66\%) & $2(6 \%)$ & $39(44 \%)$ \\
\hline$>1000$ & $13(23 \%)$ & $4(13 \%)$ & 17 (19\%) \\
\hline$>500$ & $4(7 \%)$ & $9(28 \%)$ & $13(15 \%)$ \\
\hline$>100$ & $1(2 \%)$ & $2(6 \%)$ & $3(3 \%)$ \\
\hline$>50$ & $1(2 \%)$ & $5(15 \%)$ & $6(7 \%)$ \\
\hline$<50$ & $0(0 \%)$ & $10(31 \%)$ & $10(11 \%)$ \\
\hline
\end{tabular}

${ }^{*}$ CPAP as ceiling care. The patient was not deemed clinically appropriate for mechanical ventilation.

†Self-reported.

BMI, body mass index; COPD, chronic obstructive pulmonary disease; CPAP, continuous positive airway pressure; IMV, invasive mechanical ventilation; OSA, obstructive sleep apnoea.

offered either to avoid the use of IMV or as a ceiling of treatment. $^{5}$

Due to the scale of the pandemic across the UK, in many hospitals overwhelming the capacity of critical care units, CPAP was often delivered in respiratory surge units outside a traditional critical care environment. ${ }^{6-10}$ Emerging data from the first wave of the pandemic, including from our unit in Liverpool, suggest promising outcomes following the use of CPAP in such settings, with between $40 \%$ and $63 \%$ of those patients deemed appropriate for full escalation of care avoiding IMV $^{6-810} \mathrm{~A}$ large prospective study from Italy has also reported positive results with $498 / 778(62.4 \%)$ of patients avoiding intubation. ${ }^{11}$ Higher $\mathrm{C}$ reactive proteins, lower $\mathrm{PaO}_{2} /$ $\mathrm{FiO}_{2}$ and lower platelet counts were all associated with increased risk of CPAP failure. ${ }^{11}$

Severe COVID-19, however, disproportionately affects elderly, frail individuals with chronic comorbid illness. For many, IMV may not be offered as it carries a very high risk of failure and as such may result in unnecessary suffering. For these patients, CPAP may be offered as a ceiling of care, although experience is limited and reported outcomes variable: in a small cohort of 19 patients from Huddersfield receiving CPAP as a ceiling of care, $84 \% \mathrm{died}^{8}$; in another similar small cohort of 28 patients from Newcastle, $50 \%$ died prior to discharge. ${ }^{12}$ 
Table 2 Physiological parameters at CPAP initiation stratified by escalation status

\begin{tabular}{|c|c|c|c|}
\hline Variable & $\begin{array}{l}\text { For escalation to IMV } \\
(n=56)\end{array}$ & $\begin{array}{l}\text { CPAP ceiling of care* } \\
(n=32)\end{array}$ & $\begin{array}{l}\text { Whole cohort } \\
(n=88)\end{array}$ \\
\hline Respiratory rate pre-CPAP (median, IQR) & $30(25-36)$ & $29(24-34)$ & $30(25-35)$ \\
\hline $\mathrm{FiO}_{2}$ pre-CPAP (median, IQR) & $100(60-100)$ & $100(60-100)$ & $100(60-100)$ \\
\hline $\mathrm{SpO}_{2}$ pre-CPAP & $93(91-95)$ & $92(88-94)$ & $92(90-95)$ \\
\hline $\mathrm{SpO}_{2} / \mathrm{FiO}_{2}$ ratio & $95(92-153)$ & $94(89-151)$ & $95(92-152)$ \\
\hline Initial CPAP $\left(\mathrm{cmH}_{2} \mathrm{O}\right)$ & $10(7.5-10)$ & $10(7.5-10)$ & $10(7.5-10)$ \\
\hline Maximum CPAP $\left(\mathrm{cmH}_{2} \mathrm{O}\right)$ & $10(7.5-10)$ & $10(10-10)$ & $10(8.8-10)$ \\
\hline Initial oxygen (L/min) & $15(10-15)$ & $15(12-18)$ & $15(10-15)$ \\
\hline Enrolled in therapeutic clinical trials & $\begin{array}{l}\text { RECOVERY } 19(34 \%) \\
\text { Other† } 12(21 \%)\end{array}$ & $\begin{array}{l}\text { RECOVERY } 8(25 \%) \\
\text { Other† } 0(0 \%)\end{array}$ & $\begin{array}{l}\text { RECOVERY } 27(31 \%) \\
\text { Other† } 12(14 \%)\end{array}$ \\
\hline
\end{tabular}

With unprecedented research efforts, the standard medical management of COVID-19 has evolved rapidly to incorporate treatments such as dexamethasone and, in some circumstances, remdesivir and IL6 antagonists. The optimal modality of respiratory support, and anticipated outcomes, may vary with therapeutic advances. Within this context of evolving medical management, we report the outcomes of a cohort of patients hospitalised during the second wave of the COVID-19 pandemic in the UK who received CPAP within a respiratory surge unit either as a trial to avoid IMV or as a ceiling of care.

\section{METHODS}

Setting and design

We conducted a retrospective cohort analysis of patients who received CPAP for the treatment of respiratory failure secondary to COVID-19 on the respiratory surge unit of the Royal Liverpool Hospital (part of Liverpool University Hospitals NHS Foundation Trust) from 21 September 2020 (when the surge of admissions during the UK second wave necessitated reopening the unit) until 30 November 2020. Anonymised data were collected in real time by clinicians involved in patients' care as part of a service evaluation project registered with the Trust's Clinical Audit service (CAMS 9942).

\section{Participants}

All patients admitted to the respiratory surge unit who were treated with CPAP for type 1 respiratory failure secondary to COVID-19 were included in the analysis, regardless of escalation status, medical history or anticipated prognosis. All patients had a positive nasopharyngeal PCR swab for SARS-CoV-2 and/or a clinical diagnosis of COVID-19.

\section{Patient and public involvement}

Neither the patients nor the public were involved in the design or implementation of this study.

\section{Procedures}

The redistribution of resources required to establish the respiratory surge unit has been previously described. ${ }^{10} 13$ In brief, the unit was established in one of the hospital's infectious disease (ID) isolation wards with each patient accommodated in an individual negative pressure room and all staff wearing appropriate personal protective equipment. ${ }^{14}$ A multidisciplinary team consisting of ID and respiratory medical staff, ID and respiratory nurses and a respiratory physiotherapist, supported by critical care clinicians and outreach teams, was established to deliver the service. Extensive training in the theory and practicalities of CPAP delivery-building on the approach from the first wave-was delivered to all nonrespiratory staff by the specialist respiratory nurses and physiotherapist.

Patients were started on CPAP based on clinical assessment. Local guidelines suggested that CPAP should be considered-and discussed with the critical care teamwhen fractional inspired oxygen concentration $\left(\mathrm{FiO}_{2}\right)$ of $60 \%$ or more was required to maintain peripheral oxygen saturations at $92 \%$ or greater. A standard electrically powered non-invasive ventilator (Philips A30) was utilised with wall oxygen entrained into the circuit as per the British Thoracic Society (BTS) guidelines. ${ }^{15}$ These electrically powered machines were repurposed solely for use during the COVID-19 pandemic on the respiratory surge unit. Within ICU, CPAP was delivered via high-flow devices. $\mathrm{CPAP}$ was delivered in accordance to local policy. CPAP was started at pressure of $5 \mathrm{cmH}_{2} \mathrm{O}$, increasing to CPAP to 10 $\mathrm{cmH}_{2} \mathrm{O}$ within the first hour if required, and thereafter only escalated to a maximum of $12.5 \mathrm{cmH}_{2} \mathrm{O}$ following discussion with senior medical or specialist staff. ${ }^{13}$ Oxygen up to $30 \mathrm{~L} / \mathrm{min}$ was entrained into the circuit using a standard oxygen port and green tubing to maintain $\mathrm{SpO}_{2}$ of between $92 \%$ and $96 \%$. A non-vented oral-nasal mask was used and changed to full face (visor style) masks if required. A viral filter was placed upstream of the exhalation port in the circuit and was changed every 24 hours. ${ }^{14}$ 


\begin{tabular}{|c|c|c|c|}
\hline Variable & $\begin{array}{l}\text { For escalation } \\
\text { to IMV }(n=56)\end{array}$ & $\begin{array}{l}\text { CPAP ceiling } \\
\text { of care* } \\
(n=32)\end{array}$ & $\begin{array}{l}\text { Whole } \\
\text { cohort } \\
(n=88)\end{array}$ \\
\hline $\begin{array}{l}\text { Fully weaned } \\
\text { from CPAP }\end{array}$ & $42(75 \%)$ & $18(56 \%)$ & $60(68 \%)$ \\
\hline \multicolumn{4}{|c|}{ Fully weaned from CPAP by } \\
\hline \multicolumn{4}{|l|}{ Age (years) } \\
\hline$<50$ & $8(80 \%)$ & $1(100 \%)$ & $9(82 \%)$ \\
\hline $50-59$ & $11(69 \%)$ & $2(67 \%)$ & $13(68 \%)$ \\
\hline $60-69$ & $17(77 \%)$ & $8(89 \%)$ & $25(31 \%)$ \\
\hline $70-79$ & $6(75 \%)$ & $2(25 \%)$ & $8(50 \%)$ \\
\hline$\geq 80$ & 0 & $5(45 \%)$ & $5(45 \%)$ \\
\hline $\begin{array}{l}\text { Discharged } \\
\text { home }\end{array}$ & $42(75 \%)$ & $18(56 \%)$ & $60(68 \%)$ \\
\hline \multicolumn{4}{|c|}{ Increased support at discharge } \\
\hline LTOT & $0(0 \%)$ & $3(17 \%)$ & $3(5 \%)$ \\
\hline $\begin{array}{l}\text { New/increased } \\
\text { POC }\end{array}$ & $0(0 \%)$ & $5(28 \%)$ & $5(6 \%)$ \\
\hline $\begin{array}{l}\text { Days on CPAP } \\
\text { (median, IQR) }\end{array}$ & $6(4-7)$ & $9(7-11)$ & $6(4-8)$ \\
\hline $\begin{array}{l}\text { Length of stay } \\
\text { (days; median, } \\
\text { IQR) }\end{array}$ & $13(9-19)$ & $24(18-29)$ & $15(10-24)$ \\
\hline $\begin{array}{l}\text { Needed CPAP in } \\
\text { ICU but not IMV }\end{array}$ & $11(20 \%)$ & $0(0 \%)$ & $11(13 \%)$ \\
\hline IMV post CPAP & $14(25 \%)$ & & $14(16 \%)$ \\
\hline $\begin{array}{l}\text { Time to IMV } \\
\text { (CPAP fail) in } \\
\text { hours }\end{array}$ & $\begin{array}{l}\text { Median } 156 \\
(42-216), \text { mean } \\
136 \text { (SD 97) }\end{array}$ & & $\begin{array}{l}\text { Median } 156 \\
(42-216), \\
\text { mean 136 } \\
(\text { SD 97) }\end{array}$ \\
\hline $\begin{array}{l}\text { Recovered after } \\
\text { IMV }\end{array}$ & $5(36 \%)$ & & $5(36 \%)$ \\
\hline 30-day mortality & $9(16 \%)$ & $14(44 \%)$ & $23(26 \%)$ \\
\hline
\end{tabular}

${ }^{*} \mathrm{CPAP}$ as ceiling care. The patient was not deemed clinically appropriate for mechanical ventilation.

CPAP, continuous positive airway pressure; IMV, invasive mechanical ventilation; LTOT, long-term oxygen therapy; POC, package of care.

Patients were given minimal breaks (oral intake and pressure relief only) during the first 36 hours of treatment and if clinically stable, weaning thereafter was protocolised (see online supplemental material), with scope for tailoring to individual circumstances after specialist discussion. For safety reasons, patients were only proned if they were able to independently self-prone. Most were unable to do this and therefore proning was not used extensively within this cohort.

\section{Statistical methods}

Continuous variables are reported as mean (with standard deviation, $\mathrm{SD}$ ) or medians (with interquartile range, IQR) and categorical data as frequency. Patient characteristics and outcomes are stratified by CPAP indication: as a trial in patients deemed suitable to escalation to IMV; as a ceiling of care. $\mathrm{SpO}_{2} / \mathrm{FiO}_{2}$ ratio was calculated as marker of severity of acute respiratory distress syndrome (ARDS) as arterial lines allowing for regular arterial blood gases were not used in this setting. ${ }^{16}$ Odds ratios (ORs) and logistic regression modes were used to determine predictors of 30-day all-cause mortality. Predictors were selected a priori. Data were analysed using Stata V.14.2 statistical software. Statistical significance was tested at the $5 \%$ level.

\section{RESULTS}

\section{Patient characteristics and clinical presentation}

There was 1042 confirmed SARS-CoV-2 patients diagnosed between 21 September and 30 November 2020. One hundred and sixteen were admitted to critical care and 88 patients received CPAP on the respiratory surge unit. Of those $88,56 / 88(64 \%)$ were deemed eligible for escalation to critical care and IMV and 32/88 (36\%) received CPAP as a ceiling of care. The median age was 63 years (IQR: 56-74) and 58/88 (66\%) were male (table 1). Those for whom CPAP was the ceiling of care were older, with 11/32 (34\%) being 80 years or above and more frail (median clinical frailty scale 4 (IQR: $3-5$ ) vs 1 (IQR: 1-2)). Recognised risk factors for severe COVID-19 were frequent across both groups: hypertension $(50 / 88$, $57 \%)$, type 2 diabetes $(32 / 88,36 \%)$, elevated body mass index (BMI; median 31; IQR: 28-34). Of those in the CPAP as ceiling of care category, $80 \%$ of patients had an exercise tolerance of $500 \mathrm{~m}$ or less.

On admission to the surge unit, most patients were receiving oxygen delivered at $15 \mathrm{~L} / \mathrm{min}$ via a nonrebreathe mask (documented as $100 \%$ oxygen; median pre-CPAP $\mathrm{FiO}_{2}$ was $100 \%$ (IQR 60\%-100\%; table 2). Median $\mathrm{SpO}_{2}$ immediately prior to CPAP initiation was 92\% (IQR 90\%-95\%) with an $\mathrm{SpO}_{2} / \mathrm{FiO}_{2}$ ratio of 95 (92152). Median starting CPAP (ie, highest airway pressure administered within the first hour) was $10 \mathrm{cmH}_{2} \mathrm{O}$ (IQR $7.5-10)$ and the median oxygen flow rate was $15 \mathrm{~L} / \mathrm{min}$ $(10-15 \mathrm{~L} / \mathrm{min})$.

\section{Outcomes}

Thirty-day outcome data were available for all patients. For the overall cohort, 30-day all-cause mortality was 23/88 (26\%; table 3 ). At the time of writing, all surviving patients had been weaned from CPAP or IMV support; $1 / 88(1.1 \%)$ patient remains in hospital requiring further rehabilitation.

In those who were for full escalation to IMV, the median time on CPAP was 6 days (IQR 4-7) and median length of hospital stay was 15 days (IQR 10-24). Forty-seven (84\%) of 56 survived to day 30. Fourteen (25\%) of 56 were escalated to IMV, of whom $5 / 14(36 \%)$ survived to day 30 (figure 1). A further 11/56 (20\%) were transferred to the critical care unit but did not receive IMV: 6/11 patients required continued closer nursing supervision or delivery of CPAP via hood (which was incompatible with CPAP device on ward); 5/11 patients were taken to ICU as a precaution because the need for intubation was thought to be imminent. Overall, 42/56 (75\%) avoided 


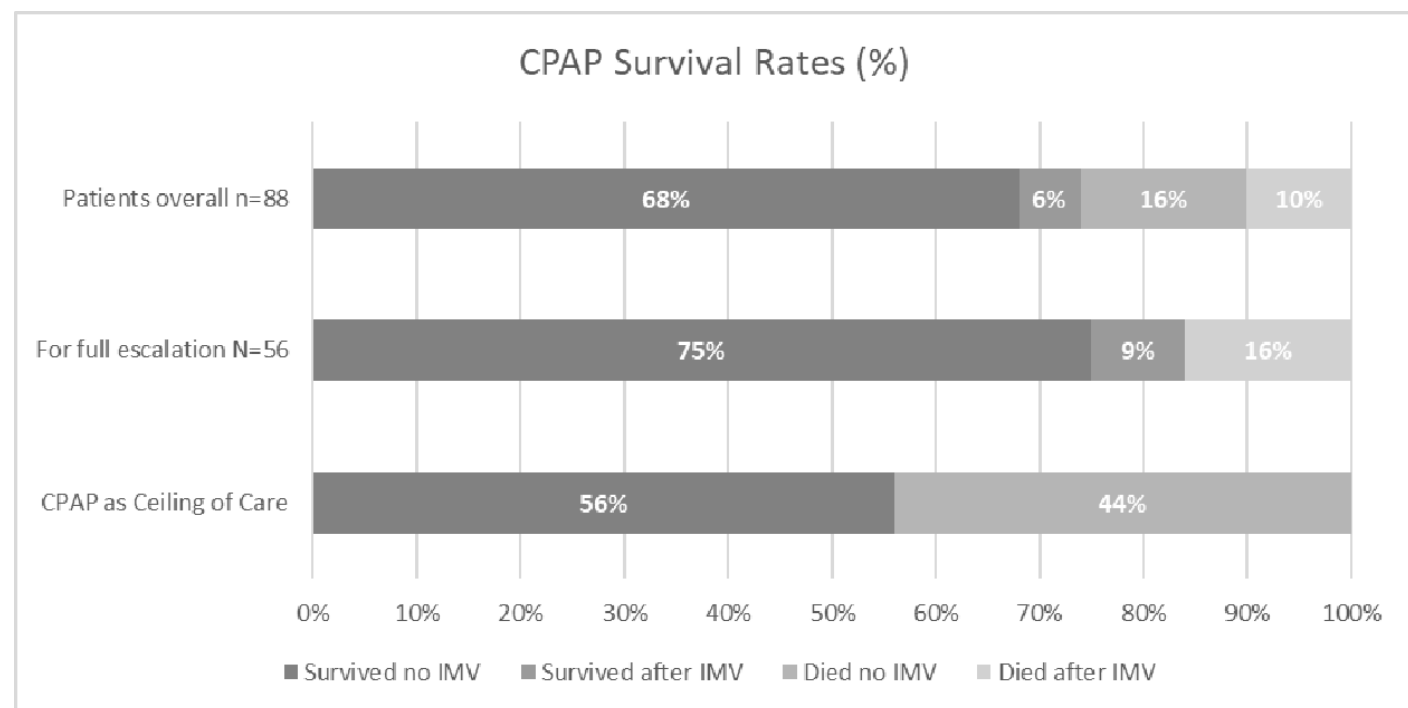

Figure 1 Thirty-day survival following CPAP stratified by escalation status. CPAP, continuous positive airway pressure; IMV, invasive mechanical ventilation.

IMV. None required long-term oxygen therapy (LTOT) at discharge.

Of those patients for whom CPAP was ceiling of care, the median duration of CPAP was 9 days (IQR 7-11) and the median length of hospital stay in those who survived to discharge was 24 days (IQR 18-29). Two patients required weaning to high flow oxygen (AIRVO 2 with supplemental oxygen) prior to standard wall oxygen. Eighteen $(56 \%)$ of 32 survived to day 30, all of whom have been discharged home. Three $(17 \%)$ of 18 had persistent hypoxia requiring LTOT and 5/18 (28\%) required a new or increased package of care (POC). Five $(45 \%)$ of 11 in the over 80 age group successfully weaned and discharged. Only one patient was readmitted within 30 days following discharge and has since been discharged again back to their normal residence.

Pulmonary barotrauma (pneumothorax, pneumomediastinum and surgical emphysema) occurred in $8 / 88$ $(9 \%)$ of patients, with 2 requiring intercostal drainage.

\section{Associations with 30 -day mortality}

In bivariable analysis, those over the age of 80 years were at significantly higher odds of death (OR: 12.0; 95\% CI: 1.1 to 128.8 ) as were those who had an exercise tolerance of less than $500 \mathrm{~m}$ but greater than $100 \mathrm{~m}$ (OR: 5.3; 95\% CI: 1.4 to 20.8) (table 4). The ISARIC mortality score was associated with 30-day mortality, with OR 1.03 (95\% CI: 1.0 to 1.1) for each percentage point increase. None of the assessed factors were independently associated with mortality in multivariant analysis in either the full or any reduced models (table 4).

\section{DISCUSSION}

We present the outcomes of a cohort of patients with severe COVID-19 who received CPAP on a respiratory surge unit during the second wave of the pandemic in the UK. Despite most having severe respiratory failure, as demonstrated by a median $\mathrm{SpO}_{2} / \mathrm{FiO}_{2}$ ratio of 95 prior to initiation of CPAP, we report an overall survival to 30 days of $74 \%$. Among those eligible for IMV who received CPAP as trial, three-quarters avoided IMV and $84 \%$ survived to day 30 . Notably, survival to 30 days was $56 \%$ for those who received CPAP as a ceiling a care-a group of patients for whom outcome data are presently scarce-although morbidity in this group was substantial with several requiring LTOT and almost one-third a new or increased social care input at discharge.

In the absence of any data from randomised controlled trials, the optimal approach to respiratory support in COVID-19 is not established. The RECOVERY-RS trial compares continued standard oxygen therapy to high-flow nasal oxygen and CPAP, although eligibility is restricted to those patients deemed suitable to escalation to IMV. There is however an emerging but small body of evidence from observational series reporting the outcomes of CPAP in COVID-19, to which our data contribute. Experience on the use of CPAP in Italian centres early in the first wave of the global pandemic was mixed. A single-centre cohort from early March 2020 reported $90 \%$ of patients who received CPAP either died or received IMV. ${ }^{17}$ A large multicentre study of 537 patients admitted from March to mid-April 2020 reported overall survival following CPAP of $66 \%$, although $45 \%$ of those patients for escalation to IMV-who accounted for $74 \%$ of the cohort-received IMV. ${ }^{18}$ During the first wave, centres in the UK reported between $40 \%$ and $63 \%$ patients avoiding mechanical ventilation. ${ }^{6-8} 1019$ The results presented herein from a cohort hospitalised during the second wave in the UK suggest improved outcomes. Clearly, there are multiple potential explanations, such as evolving standard of care including routine use of dexamethasone, improved familiarity of medical staff with a novel disease process and also more judicious patient selection for non-invasive 
Table 4 Bi-variant and multiple variant logistic regression of 30-day mortality

\begin{tabular}{|c|c|c|c|c|}
\hline \multirow[b]{2}{*}{ Variable } & \multicolumn{2}{|c|}{ Bivariable analysis } & \multicolumn{2}{|c|}{ Multivariable analysis } \\
\hline & OR & $(95 \% \mathrm{Cl})$ & OR & $(95 \% \mathrm{Cl})$ \\
\hline \multicolumn{5}{|l|}{ Age (years) } \\
\hline$<50$ & 1.0 & - & 1.0 & - \\
\hline $50-59$ & 2.6 & 0.3 to 27.5 & 2.6 & 0.2 to 37.8 \\
\hline $60-69$ & 1.9 & 0.2 to 18.6 & 1.8 & 0.1 to 41.6 \\
\hline $70-79$ & 7.8 & 0.8 to 76.1 & 5.4 & 0.1 to 313.6 \\
\hline$\geq 80$ & 12.0 & 1.1 to $128.8^{*}$ & 9.7 & 0.1 to 1116.5 \\
\hline \multicolumn{5}{|l|}{ Sex } \\
\hline Male & 1.0 & - & 1.0 & - \\
\hline Female & 0.4 & 0.1 to 1.3 & 0.6 & 0.1 to 3.0 \\
\hline BMI $\left(\mathrm{kg} / \mathrm{m}^{2}\right)$ & 0.9 & 0.9 to 1.0 & 1.04 & 0.9 to 1.22 \\
\hline Pre-hospital symptom duration & 1.1 & 0.9 to 1.2 & 1.1 & 0.9 to 1.4 \\
\hline Diabetes & 0.9 & 0.3 to 2.4 & 0.9 & 0.2 to 38.6 \\
\hline Hypertension & 1.3 & 0.5 to 3.3 & 2.0 & 0.3 to 12.0 \\
\hline Asthma & 0.3 & 0.1 to 2.7 & 2.7 & 0.2 to 38.6 \\
\hline COPD & 0.5 & 0.1 to 5.0 & 0.1 & 0.1 to 1.8 \\
\hline Other cardiac condition & 0.9 & 0.3 to 2.7 & 1.2 & 0.2 to 8.4 \\
\hline OSA & 2.0 & 0.3 to 12.6 & 37.4 & 1.2 to 1204.8 \\
\hline Other comorbid illness $†$ & 0.7 & 0.3 to 1.8 & 0.2 & 0.2 to 1.1 \\
\hline \multicolumn{5}{|l|}{ Smoked } \\
\hline Never & 1.0 & & 1.0 & - \\
\hline Ever/current & 1.5 & 0.6 to 4.0 & 2.63 & 0.6 to 12.3 \\
\hline Clinical frailty scale ${ }^{22}$ & 1.2 & 0.9 to 1.6 & 1.5 & 0.5 to 5.0 \\
\hline Mortality $4 \mathrm{C}$ score ${ }^{23}$ & 1.03 & 1.0 to $1.1^{*}$ & 1.0 & 0.91 to 1.05 \\
\hline \multicolumn{5}{|l|}{ Exercise tolerance $(\mathrm{m}) \ddagger$} \\
\hline$>1500$ & 1.0 & - & 1.0 & - \\
\hline$>1000$ & 1.9 & 0.5 to 7.2 & 2.04 & 0.3 to 12.0 \\
\hline$>500$ & 5.3 & 1.4 to $20.8^{*}$ & 5.3 & 0.53 to 54.8 \\
\hline$>100$ & 2.3 & 0.2 to 28.9 & - & - \\
\hline$>50$ & 0.9 & 0.1 to 9.1 & 0.7 & 0.9 to 1.4 \\
\hline$<50$ & 1.2 & 0.2 to 6.6 & 0.2 & 0.0 to 41.6 \\
\hline
\end{tabular}

*Significant at $\mathrm{p}<0.05$.

†Other significant clinical past medical history.

$\ddagger$ Self-reported.

BMI, body mass index; COPD, chronic obstructive pulmonary disease; OSA, obstructive sleep apnoea.

respiratory support. Nonetheless, the apparent improved survival rates coupled with reduced requirement for IMV in severe COVID-19 are encouraging.

There is limited data reporting the outcomes of patients with COVID-19 receiving CPAP as ward-based ceiling of care. The two available case series from the UK, both from the first wave of the pandemic, report survival rates of $50 \%$ and $19 \%$ in cohorts of 28 and 19 patients, respectively. ${ }^{812}$ The multicentre Italian cohort mentioned above report $27 \%$ survival at 60 days among 140 patients receiving CPAP as a ceiling of care, although results were variable with another centre reporting an $83 \%$ survival rate (53 patients) in those who received CPAP. ${ }^{20}$ Our series with $56 \%$ survival rate in this patient group compares favourably to these previous reports and we suggest supports the current NHS England recommendation to consider offering CPAP as a ceiling of care.

The potential benefits of CPAP must be appropriately weighed against its potential burdens. Our data do highlight a risk of pulmonary barotrauma: $9 \%$ of our patients developed pneumomediastinum, surgical emphysema or pneumothorax. We did not observe barotrauma in association with the use of CPAP during the first wave of the pandemic, although it has been reported by other centres following the use of both invasive and noninvasive positive pressure ventilation. ${ }^{21}$ We encourage clinicians to be alert to this as a cause of deterioration on CPAP. 
To our knowledge, this is the first description of outcomes following CPAP for severe COVID-19 during the second wave of the pandemic in the UK and is among the largest UK cohorts described to date. Nevertheless, as a retrospective description of a cohort without a control group, we recognise that this analysis has inherent limitations. While local guidelines were developed to guide the use of CPAP, the decision to offer CPAP represents a clinical judgement: we do not describe here outcomes of patients who, for example, continued with standard oxygen therapy or were directly admitted to critical care. Factors such as disease severity, premorbid functional status, critical care bed availability and more subtle considerations such as body habitus and work of breathing factors were all likely to influence the decisions on whether or not to offer CPAP on the respiratory surge unit. The data are derived from a single centre which limits generalisability. Pending the availability of evidence from randomised controlled trials, however, observational data such as these have a role to play both in guiding management decisions and, importantly, informing discussions with patients and their families.

In conclusion, CPAP represents a feasible and potentially efficacious option for the treatment of type 1 respiratory failure in COVID-19 that-in the context of surges of disease that temporarily overwhelm critical care bed capacity - may be delivered outside the traditional critical care, thus relieving pressure on critical care beds. Our data support the NHS England recommendation to consider CPAP as a ceiling of care for those in whom admission to the ICU is not deemed appropriate and can inform clinicians and patients in making decisions about care.

\section{Author affiliations}

${ }^{1}$ Clinical Sciences, Liverpool School of Tropical Medicine, Liverpool, UK ${ }^{2}$ Department of Respiratory Medicine, Tropical and Infectious Disease Unit, Intensive care Unit, Liverpool University Hospitals NHS Foundation Trust, Liverpool, UK

${ }^{3}$ Institute of Infection, Veterinary and Ecological Sciences, Univeristy of Liverpool, Liverpool, UK

${ }^{4}$ School of Medicine, Univeristy of Liverpool, Liverpool, UK

Acknowledgements The establishment of the COVID-19 Respiratory Surge Unit represented a collaboration of the Respiratory, Infectious Diseases and Critical Care teams at the Royal Liverpool Hospital. We gratefully acknowledge the contribution of all the nursing, medical and managerial staff involved. In particular, we would like to thank the ward manager and respiratory and infectious diseases matrons, and the critical care outreach team, respiratory physiotherapists and specialist respiratory nurses who supported the unit.

Contributors Study concept and design: RN, JL, CS, SK, H Bond, H Burhan, TF, TB MB, PH, MG, ST, GJ, SA; data collection: RN, KRM, LJ, CS, ST, GJ, SA; data analysis: RN, JL, GJ, SA; data interpretation: RN, JL, LJ, GJ, SA. All authors read and gave input for the draft and final copies of this manuscript.

Funding The authors have not declared a specific grant for this research from any funding agency in the public, commercial or not-for-profit sectors.

Competing interests None declared.

Patient consent for publication Not required.

Provenance and peer review Not commissioned; externally peer reviewed.

Data availability statement Data are available upon reasonable request. Data is available upon reasonable request to the corresponding author. rebecca. nightingale@Istmed.ac.uk.
Supplemental material This content has been supplied by the author(s). It has not been vetted by BMJ Publishing Group Limited (BMJ) and may not have been peer-reviewed. Any opinions or recommendations discussed are solely those of the author(s) and are not endorsed by BMJ. BMJ disclaims all liability and responsibility arising from any reliance placed on the content. Where the content includes any translated material, BMJ does not warrant the accuracy and reliability of the translations (including but not limited to local regulations, clinical guidelines, terminology, drug names and drug dosages), and is not responsible for any error and/or omissions arising from translation and adaptation or otherwise.

Open access This is an open access article distributed in accordance with the Creative Commons Attribution Non Commercial (CC BY-NC 4.0) license, which permits others to distribute, remix, adapt, build upon this work non-commercially, and license their derivative works on different terms, provided the original work is properly cited, appropriate credit is given, any changes made indicated, and the use is non-commercial. See: http://creativecommons.org/licenses/by-nc/4.0/.

ORCID iD

Rebecca Nightingale http://orcid.org/0000-0001-5636-8531

\section{REFERENCES}

1 Dong E, Du H, Gardner L. An interactive web-based dashboard to track COVID-19 in real time. Lancet Infect Dis 2020;20:533-4.

2 Government U. Coronavirus (COVID-19) in the UK, 2020. Available: https://coronavirus.data.gov.uk/details

3 Centers for Disease C. Interim clinical guidance for management of patients with confirmed coronavirus disease (COVID-19), 2020 Available: https://www.cdc.gov/coronavirus/2019-ncov/hcp/clinicalguidance-management-patients.html

4 Docherty AB, Harrison EM, Green CA, et al. Features of 20133 UK patients in hospital with covid-19 using the ISARIC WHO Clinical Characterisation Protocol: prospective observational cohort study. BMJ 2020;369:m1985

5 NICE. Guidance for the role and use of non-invasive respiratory support in adult patients with coronavirus (confirmed or suspected), 2020.

6 Alviset S, Riller Q, Aboab J, et al. Continuous positive airway pressure (CPAP) face-mask ventilation is an easy and cheap option to manage a massive influx of patients presenting acute respiratory failure during the SARS-CoV-2 outbreak: a retrospective cohort study. PLoS One 2020;15:e0240645.

7 Ashish A, Unsworth A, Martindale J, et al. Cpap management of COVID-19 respiratory failure: a first quantitative analysis from an inpatient service evaluation. BMJ Open Respir Res 2020;7:e000692.

8 Walker J, Dolly S, Ng L, et al. The role of CPAP as a potential bridge to invasive ventilation and as a ceiling-of-care for patients hospitalized with Covid-19-An observational study. PLoS One 2020;15:e0244857.

9 Lawton T, Wilkinson KM, Javid R. Reduced ICU demand with early CPAP and proning in COVID-19 at Bradford: a single centre cohort. medRxiv 2020. doi:10.1101/2020.06.05.20123307

10 Nightingale R, Nwosu N, Kutubudin F, et al. Is continuous positive airway pressure (CPAP) a new standard of care for type 1 respiratory failure in COVID-19 patients? A retrospective observational study of a dedicated COVID-19 CPAP service. BMJ Open Respir Res 2020;7:e000639.

11 Bellani G, Grasselli G, Cecconi M, et al. Noninvasive ventilatory support of patients with COVID-19 outside the intensive care units (WARd-COVID). Ann Am Thorac Soc 2021;18:1020-6. doi:10.1513/ AnnalsATS.202008-10800C

12 Burns GP, Lane ND, Tedd HM, et al. Improved survival following ward-based non-invasive pressure support for severe hypoxia in a cohort of frail patients with COVID-19: retrospective analysis from a UK teaching hospital. BMJ Open Respir Res 2020;7:e000621.

13 Robinson RE, Nightingale R, Frost F, et al. The rapid development and deployment of a new multidisciplinary CPAP service outside of a critical care environment during the early stages of the COVID-19 pandemic. Future Healthc J 2021;8:e156-9.

14 England N. Guidance for the role and use of non-invasive respiratory support in adult patients with COVID-19 (confirmed or suspected), 2020. Available: https://www.england.nhs.uk/coronavirus/wpcontent/uploads/sites/52/2020/03/specialty-guide-NIV-respiratorysupport-and-coronavirus-v3.pdf

15 BTS. Use of acute NIV in patients hospitalised with suspected or confirmed COVID-19 infection, 2020. Available: https://www. brit-thoracic.org.uk/media/455095/advice-on-acute-niv-technicalaspects-final-16-march-2020.pdf 
16 Chen W, Janz DR, Shaver CM, et al. Clinical characteristics and outcomes are similar in ARDS diagnosed by oxygen saturation/Fio2 ratio compared with Pao2/Fio2 ratio. Chest 2015;148:1477-83.

17 Duca A, Memaj I, Zanardi F, et al. Severity of respiratory failure and outcome of patients needing a ventilatory support in the emergency department during Italian novel coronavirus SARS-CoV-2 outbreak: preliminary data on the role of helmet CPAP and non-invasive ventilation. SSRN 2020. doi:10.2139/ssrn.3566170

18 Vaschetto R, Barone-Adesi F, Racca F, et al. Outcomes of COVID-19 patients treated with continuous positive airway pressure outside the intensive care unit. ERJ Open Res 2021;7. doi:10.1183/23120541.00541-2020. [Epub ahead of print: $25 \mathrm{Jan}$ 2021].

19 Ahmed YN, Gokaraju S, Powrie D. Predictors of CPAP outcome in hospitalised COVID-19 patients. medRxiv 2020.
20 Brusasco C, Corradi F, Di Domenico A, et al. Continuous positive airway pressure in COVID-19 patients with moderate-to-severe respiratory failure. Eur Respir J 2021;57. doi:10.1183/13993003.02524-2020. [Epub ahead of print: 17 Feb 2021].

21 Mart MF, Norfolk SG, Flemmons LN. Pneumomediastinum in ARDS from COVID-19 infection. Am J Respir Crit Care Med 2020.

22 Rockwood K, Song X, MacKnight C, et al. A global clinical measure of fitness and frailty in elderly people. CMAJ 2005;173:489-95.

23 Knight SR, Ho A, Pius R, et al. Risk stratification of patients admitted to hospital with covid-19 using the ISARIC who clinical characterisation protocol: development and validation of the $4 \mathrm{C}$ mortality score. BMJ 2020;370:m3339. 